\title{
Complications following surgery with or without radiotherapy or radiotherapy alone for prostate cancer
}

C J D Wallis ${ }^{1}$, P Cheung ${ }^{2}$, S Herschorn ${ }^{1}$, R Saskin ${ }^{3}$, J Su ${ }^{3}, \mathrm{~L} \mathrm{H} \mathrm{Klotz}{ }^{1}$, G S Kulkarni ${ }^{4}$, Y Lee ${ }^{5}$, R T Kodama ${ }^{1}$, $\mathrm{S} A \mathrm{Narod}^{6}$ and R K Nam${ }^{*, 1}$

${ }^{1}$ Division of Urology, Toronto, ON, Canada M4N3M5; ${ }^{2}$ Department of Radiation Oncology, Toronto, ON, Canada M4N3M5; ${ }^{3}$ Institute of Evaluative Clinical Sciences, Sunnybrook Health Sciences Centre, Sunnybrook Research Institute, University of Toronto, 2075 Bayview Ave., Toronto, ON, Canada M4N3M5; ${ }^{4}$ Division of Urology, University Health Network, University of Toronto, 610 University Ave., Toronto, ON, Canada M5G2M9; ${ }^{5}$ Department of Medicine, St Michael's Hospital, University of Toronto, 30 Bond St, Toronto, ON, Canada M5B1W8 and ${ }^{6}$ Department of Public Health Sciences, University of Toronto, 790 Bay St, Toronto, ON, Canada M5G1N8

Background: Men undergoing treatment of clinically localised prostate cancer may experience a number of treatment-related complications, which affect their quality of life.

Methods: On the basis of population-based retrospective cohort of men undergoing surgery, with or without subsequent radiotherapy, or radiotherapy alone for prostate cancer in Ontario, Canada, we measured the incidence of treatment-related complications using administrative and billing data.

Results: Of 36984 patients, 15870 (42.9\%) underwent surgery alone, 4519 (12.2\%) underwent surgery followed by radiotherapy, and 16595 (44.9\%) underwent radiotherapy alone. For all end points except urologic procedures, the 5-year cumulative incidence rates were lowest in the surgery only group and highest in the radiotherapy only group. Intermediary rates were seen in the surgery followed by radiotherapy group, except for urologic procedures where rates were the highest in this group. Although age and comorbidity were important predictors, radiotherapy as the primary treatment modality was associated with higher rates for all complications (adjusted hazard ratios 1.6-4.7, $P=0.002$ to $<0.0001$ ).

Conclusions: In patients treated for prostate cancer, radiation after surgery increases the rate of complications compared with surgery alone, though these rates remain lower than patients treated with radiation alone. This information may inform patient and physician decision making in the treatment of prostate cancer.

Treatment options for patients with clinically localised prostate cancer include radical prostatectomy and radiotherapy (Barry et al, 2001; Kibel et al, 2012; Sooriakumaran et al, 2014). Treatment choice is affected in large part by patient and provider preference. It is important for patients to understand the frequencies and severities of the complications associated with each treatment modality in addition to their cancer control rates.
Although complications following treatment for prostate cancer typically focus on urinary incontinence and erectile dysfunction (Potosky et al, 2004), we recently demonstrated in a populationbased cohort study of 32465 men that treatment-related complications were more common among prostate cancer patients who underwent radiation treatment alone compared with those who had surgery alone (Nam et al, 2014). Patients who underwent 
radiotherapy experienced higher rates of hospital admission, minimally invasive urologic procedures, rectal-anal procedures, open surgical procedures and secondary malignancies than those patients who underwent radical prostatectomy.

This study was limited only among men undergoing surgery or radiotherapy alone. Following radical prostatectomy, a proportion of men will undergo subsequent radiotherapy. This may be with adjuvant or salvage intent. It would be important to examine the complication rates of patients treated not only with surgery or radiotherapy alone but also those that received radiotherapy following surgery. We examined an additional 4519 men who underwent surgery followed by radiotherapy and compared their rates of complications in the previously defined five categories to men treated with either surgery or radiation monotherapy.

\section{MATERIALS AND METHODS}

Study population. The study design and subjects have previously been described by Nam et al (2014). In short, we conducted a population-based, retrospective cohort study of men aged 18 years and older who underwent treatment of clinically localised prostate cancer in Ontario, Canada between 2002 and 2009. Patients were included if they underwent radical prostatectomy with or without subsequent radiotherapy or primary radiotherapy. Patients undergoing salvage prostatectomy (surgery after radiotherapy) were excluded as were patients that underwent a laparoscopic or robotic prostatectomy as these technologies were not widely adopted in Ontario during the study interval.

In Ontario, all medical procedures are reimbursed through a single-payer, government-operated health insurance system (the Ontario Health Insurance Plan; OHIP). We used physician billing codes linked to prostate cancer diagnostic codes to identify patients undergoing radical prostatectomy and radiotherapy for prostate cancer. In order to exclude patients undergoing palliative radiotherapy, we exclude those with a diagnostic code for metastasis and those who died within 5 years of treatment.

We then linked these records with the Canadian Institute for Health Information (CIHI) hospital discharge database, the Ontario Cancer registry, and the Registered Persons database. The study protocol was approved by the Sunnybrook Health Sciences Centre Research Ethics Board.

Outcome measures. Five different outcome measures were used to assess treatment-related complications: (1) those requiring a hospital admission for management; (2) those requiring a minimally invasive urologic procedure; (3) those requiring a rectal or anal procedure; (4) those requiring an open surgical procedure related to the urinary tract, rectum, or anus; and (5) the development of a secondary malignancy at any cancer site. The definition of each category has been previously published (Nam et al, 2014). Repeated procedures were not captured.

Data analysis. We conducted Kaplan-Meier survival analysis for each outcome in order to estimate their cumulative incidence. Because these complications are not mutually exclusive, each analysis was run separately. For the first four outcome measures, patients were considered at risk from the date of the completion of their therapy until an event, death, or the last date of follow-up. For those patients who underwent surgery followed by radiotherapy, they were considered at risk from the date of initial therapy. For the development of secondary malignancies, we considered patients at risk beginning 5 years from the date of treatment in order to allow for a 5-year lag time from the date of radiation exposure to the secondary cancer's development (Berrington deGonzalez et al, 2011).

We then estimated the hazard ratio (HR) for developing an event, adjusted for several identified covariates, using Cox proportional hazard modelling. Identified covariates included patient's age, comorbidity at the time of treatment, treatment year and the index treatment. Comorbidity was measured using the sum of aggregated disease groups (ADG) based on the Johns Hopkins University ACG Case-Mix System (Center, 2005).

For each outcome measure, we tested the proportional hazards assumption using the Schoenfeld residuals method. The Pearson correlation coefficients of Schoenfeld residuals of the treatment covariate and time, logarithm of time, and square root of time were calculated. If we recorded significant associations $(P<0.05)$ for all three correlation coefficients, the proportional hazards assumption was not met. In this case, we calculated the adjusted HRs at yearly intervals (years 1-5).

In order to account for baseline differences between the two groups that are not controlled by multivariate analysis, we undertook propensity-score matching. The propensity score was composed of age, ADG comorbidity score, and year of treatment. Matching was performed based on nearest-neighbour matching using a caliper width of 0.2 for the propensity score.

\section{RESULTS}

A total of 36984 patients underwent treatment for clinically localised prostate cancer between 1 January 2002 and 31 December 2009. Of these, 15870 (42.9\%) underwent surgery alone, 4519 (12.2\%) underwent surgery followed by radiation, and 16595 (44.9\%) underwent radiotherapy alone. Patients who underwent surgery initially were younger on average (median age 62, interquartile range 57-66) than those who received radiotherapy (median age 70, interquartile range 65-75). Similarly, the surgical group also had a lower level of comorbidity (mean ADG 5.20, s.d. 2.27) than their radiotherapy counterparts (mean ADG 5.68, s.d. 2.58).

From Kaplan-Meier survival analysis, urologic procedures were the most common complication with rates ranging from 30.0 to $42.4 \%$ depending on treatment modality (Table 1 ). The 5-year cumulative rates of complications for patients who had both surgery and radiation were intermediate between the respective rates for the surgery and radiation monotherapy groups (Figure 1), except for those requiring a urologic procedure where these patients experienced the highest rates (Table 1).

Cox proportional hazard modelling was performed by comparing all patients treated initially with surgery whether or not they received subsequent radiotherapy to those treated with

Table 1. Cumulative incidence of each complication category based on Kaplan-Meier survival analysis of the risk of developing a complication, stratified by three treatment groups

\begin{tabular}{|c|c|c|c|c|c|}
\hline & Hospital admission & Urologic procedures & Rectal or anal procedures & Open surgeries & Secondary malignancy \\
\hline Surgery & $17.5(16.9-18.1)$ & $34.2(33.4-35.0)$ & $7.2(6.8-7.6)$ & $0.8(0.6-0.9)$ & $1.3(1.0-1.7)$ \\
\hline Surgery $+\mathrm{XRT}$ & $23.3(22.0-24.7)$ & $42.4(40.9-44.0)$ & $12.6(11.5-13.7)$ & $1.1(0.8-1.5)$ & $3.0(2.2-4.1)$ \\
\hline XRT & $27.0(26.2-27.8)$ & $30.0(29.2-30.9)$ & $20.4(19.7-21.1)$ & $1.1(1.0-1.4)$ & $3.7(3.1-4.3)$ \\
\hline
\end{tabular}



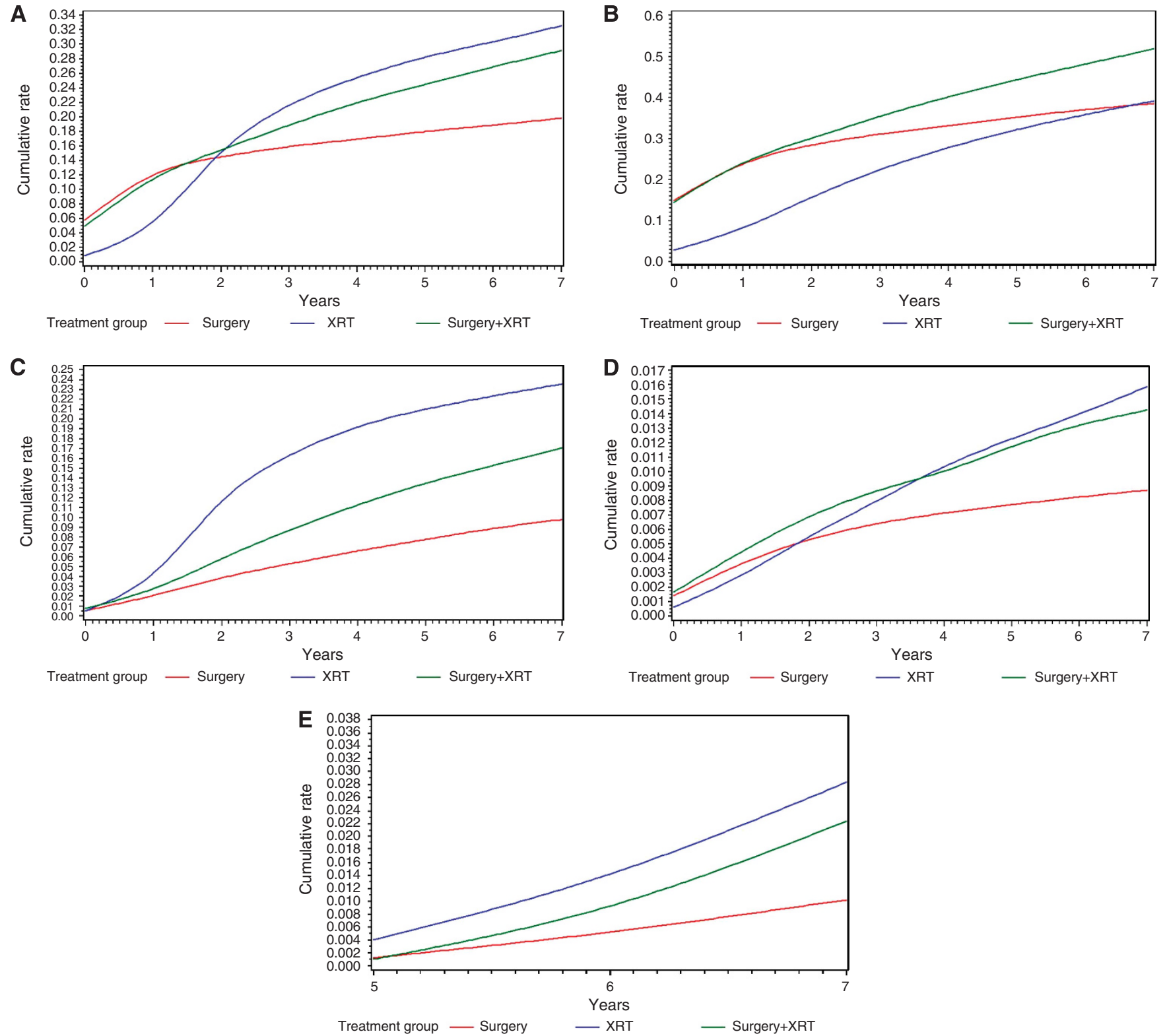

Figure 1. Kaplan Meier cumulative incidence of outcome measures by three groups (surgery alone, surgery + radiation, radiation alone).

(A) Hospital admissions; (B) urologic procedures; (C) rectal-anal procedures; (D) open surgical procedures; and (E) secondary malignancies.

radiotherapy alone in order to provide an intention to treat-style analysis. For hospital admissions, urologic procedures, and open surgical procedures, the comparison failed to meet the proportional hazard assumption, and time-dependent HRs were calculated based on a time-interaction factor. Age and comorbidity were, in general, positively associated with the risk of complications (Table 2). After adjusting for age and comorbidity, patients treated with radiotherapy alone had higher rates of complication across all categories (Table 2).

Because patients undergoing surgery initially were younger and had fewer comorbidities than those undergoing radiotherapy alone, we conducted propensity-score matching to examine the effect of their index treatment group for each outcome. A total of 9503 pairs were matched (19006 patients) using nearest-neighbour matching and a caliper score of 0.2 . In this case, only comparisons of hospital admissions and urologic procedures failed to meet the proportional hazard assumption, and time-dependent HRs were used. The HR for open surgical procedures and secondary malignancies fell to nonsignificant in this analysis; however, all other outcomes were in the same direction and similar magnitude, except for hospital admissions where the HR rose significantly favouring the surgical group (Table 3).

As radiotherapy techniques have changed significantly over time, we sought to analyse the outcomes of only those patients treated with the most modern techniques (denoted by OHIP billing code X313). Both multivariate analysis by Cox proportional hazard modelling and propensity-score analysis were undertaken. Propensity-score matched results are presented showing that the results were in the same direction and magnitude as the propensity-score matched analysis of the whole radiation cohort (Table 4).

A breakdown of the specific diagnoses and procedures in each complication category is detailed in Table 5.

\section{DISCUSSION}

We describe a large, population-based study of 36984 patients undergoing radical prostatectomy with or without subsequent radiotherapy or radical radiotherapy alone. Patients receiving 
Table 2. Multivariate analysis using Cox proportional hazard modelling to examine factors that predict the development of treatment-related complications stratified by those patients treated with surgery initially, regardless of subsequent radiotherapy and radiotherapy alone

\begin{tabular}{|c|c|c|c|c|c|}
\hline & Hospital admission & Urologic procedures & Rectal or anal procedures & Open surgeries & Secondary malignancy \\
\hline Age & $1.02(1.01-1.02, P<0.0001)$ & $1.01(1.01-1.01, P<0.0001)$ & $0.998(0.985-0.011, P=0.7723)$ & $\begin{array}{c}0.997(0.982-1.01 \\
P=0.7322\end{array}$ & $1.04(1.02-1.06, P=0.0002)$ \\
\hline $\begin{array}{l}\text { Comorbidity } \\
\text { (ADG) }\end{array}$ & $1.08(1.07-1.09, P<0.0001)$ & $1.07(1.06-1.08, P<0.0001)$ & $1.17(1.12-1.21, P<0.0001)$ & $\begin{array}{c}1.06(1.02-1.11 \\
P=0.0043)\end{array}$ & $\begin{array}{c}1.01(0.956-1.06 \\
P=0.8246)\end{array}$ \\
\hline \multicolumn{6}{|l|}{ Treatment } \\
\hline $\begin{array}{l}\text { Surgery } \pm \text { XRT } \\
\text { XRT }\end{array}$ & $\begin{array}{c}1.00 \\
1 \text { year: } 0.857(0.810-0.907 \\
P<0.0001) \\
2 \text { year: } 1.31(1.24-1.39 \\
P<0.0001) \\
3 \text { year: } 2.01(1.87-2.15 \\
P<0.0001) \\
4 \text { year: } 3.07(2.79-3.38 \\
P<0.0001) \\
5 \text { year: } 4.69(4.14-5.32 \\
P<0.0001)\end{array}$ & $\begin{array}{c}1.00 \\
1 \text { year: } 0.489(0.467-0.513, \\
P<0.0001) \\
2 \text { year: } 0.716(0.684-0.749, \\
P<0.0001) \\
3 \text { year: } 1.05(0.991-1.10 \\
P=0.0999) \\
4 \text { year: } 1.31(1.43-1.64 \\
P<0.0001) \\
5 \text { year: } 2.24(2.05-2.45 \\
P<0.0001)\end{array}$ & $\begin{array}{c}1.00 \\
2.09(1.95-2.24, P<0.0001)\end{array}$ & $\begin{array}{c}1.00 \\
1 \text { year: } 1.06(0.806-1.40, \\
P=0.6623) \\
2 \text { year: } 1.37(1.07-1.7548, \\
P=0.0132) \\
3 \text { year: } 1.76(1.34-2.32, \\
P<0.0001) \\
4 \text { year: } 2.27(1.60-3.21, \\
P<0.0001) \\
5 \text { year: } 2.92(1.88-4.53, \\
P<0.0001)\end{array}$ & $\begin{array}{c}1.00 \\
1.60(1.20-2.13, P=0.0015)\end{array}$ \\
\hline
\end{tabular}

Table 3. Multivariate analysis using Cox proportional hazard modelling of a propensity-score matched sample to examine factors that predict the development of treatment-related complications stratified by those patients treated with surgery initially, regardless of subsequent radiotherapy and radiotherapy alone

\begin{tabular}{|c|c|c|c|c|c|}
\hline & Hospital admission & Urologic procedures & Rectal or anal procedures & Open surgeries & Secondary malignancy \\
\hline Age & $\begin{array}{c}0.990(0.964-1.02 \\
P=0.4454)\end{array}$ & $0.997(0.974-1.02, P=0.8021)$ & $1.02(0.985-1.05, P=0.2863)$ & $\begin{array}{c}1.02(0.911-1.15 \\
P=0.7146)\end{array}$ & $\begin{array}{c}1.24(0.972-1.57 \\
P=0.0836)\end{array}$ \\
\hline \multicolumn{6}{|l|}{ Treatment } \\
\hline $\begin{array}{l}\text { Surgery } \pm X R T \\
X R T\end{array}$ & $\begin{array}{c}1.00 \\
1 \text { year: } 0.830(0.768-0.896 \\
P<0.0001) \\
2 \text { year: } 1.87(1.68-2.07 \\
P<0.0001) \\
3 \text { year: } 4.20(3.54-4.99 \\
P<0.0001) \\
4 \text { year: } 9.46(7.38-12.12 \\
P<0.0001) \\
5 \text { year: } 21.28(15.33-29.54 \\
P<0.0001)\end{array}$ & $\begin{array}{c}1.00 \\
1 \text { year: } 0.465(0.435-0.496 \\
P<0.0001) \\
2 \text { year: } 0.793(0.733-0.857 \\
P<0.0001) \\
3 \text { year: } 1.35(1.21-1.52 \\
P<0.0001) \\
4 \text { year: } 2.31(1.97-2.71 \\
P<0.0001) \\
5 \text { year: } 3.94(3.19-4.85 \\
P<0.0001)\end{array}$ & $\begin{array}{c}1.00 \\
2.19(1.99-2.42 \\
P<0.0001)\end{array}$ & $\begin{array}{c}1.00 \\
1.17(0.849-1.62 \\
P=0.3356)\end{array}$ & $\begin{array}{c}1.00 \\
1.54(0.822-2.87 \\
P=0.1781)\end{array}$ \\
\hline
\end{tabular}

Table 4. Multivariate analysis using Cox proportional hazard modelling of a propensity-score matched sample based on a restricted comparison of patients who had only 3D-types of radiation in order to examine factors that predict the development of treatment-related complications stratified by those patients treated with surgery initially, regardless of subsequent radiotherapy and radiotherapy alone

\begin{tabular}{|c|c|c|c|c|c|}
\hline & Hospital admission & Urologic procedures & Rectal or anal procedures & Open surgeries & Secondary malignancy \\
\hline Age & $\begin{array}{c}1.00(0.971-1.03 \\
P=0.9167)\end{array}$ & $1.00(0.975-1.03, P=0.8624)$ & $1.01(0.966-1.05, P=0.8177)$ & $\begin{array}{c}1.02(0.889-1.17 \\
P=0.7913)\end{array}$ & $\begin{array}{c}1.23(0.939-1.60 \\
P=0.135)\end{array}$ \\
\hline \multicolumn{6}{|l|}{ Treatment } \\
\hline $\begin{array}{l}\text { Surgery } \pm \text { XRT } \\
\text { XRT }\end{array}$ & $\begin{array}{c}1.00 \\
1 \text { year: } 0.816(0.745-0.893 \\
P<0.0001) \\
2 \text { year: } 1.94(1.71-2.19 \\
P<0.0001) \\
3 \text { year: } 4.60(3.73-5.66 \\
P<0.0001) \\
4 \text { year: } 10.92(8.07-14.78 \\
P<0.0001) \\
5 \text { year: } 25.93(17.38-38.68 \\
P<0.0001)\end{array}$ & $\begin{array}{c}1.00 \\
1 \text { year: } 0.437(0.404-0.472 \\
P<0.0001) \\
2 \text { year: } 0.789(0.719-0.866 \\
P<0.0001) \\
3 \text { year: } 1.43(1.24-1.64 \\
P<0.0001) \\
4 \text { year: } 2.57(2.12-3.13 \\
P<0.0001) \\
5 \text { year: } 4.65(3.60-6.01 \\
P<0.0001)\end{array}$ & $\begin{array}{c}1.00 \\
2.36(2.10-2.65, P<0.0001)\end{array}$ & $\begin{array}{c}1.00 \\
1.12(0.765-1.63 \\
P=0.5674)\end{array}$ & $\begin{array}{c}1.00 \\
1.44(0.705-2.95 \\
P=0.3158)\end{array}$ \\
\hline
\end{tabular}

surgery followed by radiotherapy had an increased risk of treatment-related complications, as measured by our five end points, compared with the baseline group of surgery alone. Notably, except for minimally invasive urologic procedures, these patients had lower risks of complications compared with patients treated with radiotherapy alone.

Although Nam et al (2014) described the rates of complications for men treated with either radical prostatectomy alone or radiotherapy alone, we know that many men following radical prostatectomy will require radiotherapy with either adjuvant or salvage intent. In the adjuvant setting, radiotherapy has been shown to decrease the risk of metastasis and prostate cancerspecific death (Thompson et al, 2009). For this reason, it is the standard of care for men at high risk for recurrence (Bolla et al, 2005). Furthermore, an estimated $25 \%$ of men who undergo radical prostatectomy for clinically localised prostate cancer will 
Table 5. Specific breakdown of procedures and diagnoses used to define complication categories

\begin{tabular}{|c|c|c|c|c|c|c|}
\hline & \multicolumn{2}{|c|}{ Surgery alone $(n=15870)$} & \multicolumn{2}{|c|}{ Surgery + radiotherapy $(n=4519)$} & \multicolumn{2}{|c|}{ Radiotherapy alone $(n=16595)$} \\
\hline & Frequency & Risk in person years & Frequency & Risk in person years & Frequency & Risk in person years \\
\hline \multicolumn{7}{|c|}{ Minimally invasive urologic procedures } \\
\hline $\begin{array}{l}\text { Cystoscopy } \\
\text { Catheterisation } \\
\text { Urethral dilatation or incision } \\
\text { Calculi or clot removal } \\
\text { Prostate biopsy }\end{array}$ & $\begin{array}{r}3107 \\
1187 \\
1003 \\
71 \\
0\end{array}$ & $\begin{array}{c}66.42 / 1000 \\
25.37 / 1000 \\
21.44 / 1000 \\
1.52 / 1000 \\
0\end{array}$ & $\begin{array}{r}1243 \\
346 \\
354 \\
30 \\
0\end{array}$ & $\begin{array}{c}102.87 / 1000 \\
28.63 / 1000 \\
29.30 / 1000 \\
2.49 / 1000 \\
0\end{array}$ & $\begin{array}{r}2852 \\
718 \\
291 \\
70 \\
655\end{array}$ & $\begin{array}{c}58.33 / 1000 \\
14.68 / 1000 \\
5.95 / 1000 \\
1.43 / 1000 \\
13.40 / 1000\end{array}$ \\
\hline \multicolumn{7}{|l|}{ Admission to hospital } \\
\hline $\begin{array}{l}\text { Gastrointestinal or genitourinary fistula } \\
\text { Genitourinary bleeding } \\
\text { Gastrointestinal bleeding } \\
\text { Renal failure } \\
\text { Infection } \\
\text { Urinary obstruction } \\
\text { Radiation proctitis } \\
\text { Radiation cystitis } \\
\text { Bladder stone }\end{array}$ & $\begin{array}{r}30 \\
165 \\
0 \\
28 \\
370 \\
2017 \\
0 \\
0 \\
139\end{array}$ & $\begin{array}{c}0.50 / 1000 \\
2.76 / 1000 \\
0 \\
0.47 / 1000 \\
6.20 / 1000 \\
33.78 / 1000 \\
0 \\
0 \\
2.33 / 1000\end{array}$ & $\begin{array}{r}<6^{\mathrm{a}} \\
161 \\
0 \\
11 \\
144 \\
239 \\
0 \\
0 \\
0\end{array}$ & $\begin{array}{c}<0.34 / 1000^{\mathrm{a}} \\
9.20 / 1000 \\
0 \\
0.63 / 1000 \\
8.23 / 1000 \\
13.66 / 1000 \\
0 \\
0 \\
0\end{array}$ & $\begin{array}{r}12 \\
587 \\
523 \\
96 \\
435 \\
531 \\
1656 \\
160 \\
0\end{array}$ & $\begin{array}{c}0.23 / 1000 \\
11.27 / 1000 \\
10.04 / 1000 \\
1.84 / 1000 \\
8.35 / 1000 \\
10.20 / 1000 \\
31.80 / 1000 \\
3.07 / 1000 \\
0\end{array}$ \\
\hline \multicolumn{7}{|l|}{ Rectal-anal procedures } \\
\hline $\begin{array}{l}\text { Excision of hemorrhoids } \\
\text { Fulguration of bleeding } \\
\text { Dilatation of anal sphincter } \\
\text { Lower GI endoscopy }\end{array}$ & $\begin{array}{l}130 \\
72 \\
<6^{a} \\
927\end{array}$ & $\begin{array}{c}1.93 / 1000 \\
1.07 / 1000 \\
<0.09 / 1000^{\mathrm{a}} \\
13.75 / 1000\end{array}$ & $\begin{array}{l}68 \\
97 \\
<6^{a} \\
420\end{array}$ & $\begin{array}{c}3.51 / 1000 \\
2.01 / 1000 \\
<0.32 / 1000^{a} \\
21.67 / 1000\end{array}$ & $\begin{array}{r}214 \\
761 \\
8 \\
1954\end{array}$ & $\begin{array}{c}3.73 / 1000 \\
13.26 / 1000 \\
0.14 / 1000 \\
34.05 / 1000\end{array}$ \\
\hline \multicolumn{7}{|l|}{ Secondary malignancy } \\
\hline Overall & 60 & $1.15 / 1000$ & 45 & $2.70 / 1000$ & 159 & $3.25 / 1000$ \\
\hline \multicolumn{7}{|l|}{ Open surgical procedures } \\
\hline $\begin{array}{l}\text { Bladder neck repair } \\
\text { Cystotomy } \\
\text { Fistula repair } \\
\text { Lymphocele drainage } \\
\text { Ureteric reimplantation } \\
\text { Cystectomy }\end{array}$ & $\begin{array}{c}35 \\
23 \\
46 \\
<6^{\mathrm{a}} \\
10 \\
0\end{array}$ & $\begin{array}{c}0.48 / 1000 \\
0.31 / 1000 \\
0.63 / 1000 \\
<0.06 / 1000^{a} \\
0.14 / 1000 \\
0\end{array}$ & $\begin{array}{r}0 \\
14 \\
15 \\
0 \\
0 \\
0\end{array}$ & $\begin{array}{c}0 \\
0.62 / 1000 \\
0.67 / 1000 \\
0 \\
0 \\
0\end{array}$ & $\begin{array}{r}0 \\
124 \\
39 \\
0 \\
0 \\
12\end{array}$ & $\begin{array}{c}0 \\
1.74 / 1000 \\
0.55 / 1000 \\
0 \\
0 \\
0.17 / 1000\end{array}$ \\
\hline
\end{tabular}

experience recurrence of their disease in the absence of further therapy (Bianco et al, 2005). This is initially manifested as a rising prostate-specific antigen (PSA) level without overt metastasis. Salvage radiotherapy is offered to these patients based on evidence that a proportion of them will achieve a durable response to salvage therapy (Stephenson et al, 2004).

Therefore, in order to more accurately counsel patients as they make their initial treatment decision, this study offers a more complete analysis comparing men treated with the initial intent of surgery or radiotherapy, including both those who received radiotherapy following surgery and those who did not.

Patients who underwent radical prostatectomy followed by radiotherapy experienced complication rates between those of patients undergoing either surgery or radiotherapy monotherapy in all categories except for urologic procedures where they experienced higher complication rates than either other group. Although it might be expected that these patients would experience the highest burden of complications owing to receiving both modalities of therapy or to a more advanced disease state, which necessitated dual therapy, this was not observed. Instead, our data support the notion of a dose-effect response with patients receiving adjuvant or salvage radiotherapy likely to receive lower doses than those receiving treatment doses (60-64 Gy as compared with 70-78 Gy (Bolla et al, 2005; Thompson et al, 2009; Kibel et al, 2012)). Thompson et al (2006), in a Phase 3 study evaluating the efficacy of adjuvant and salvage radiation, clearly showed high rates of urologic-related complications. Patients should be aware of the potential increased rates of urologic complications when considering surgery, as the need for adjuvant or salvage radiation is possible.

Patients with locally advanced prostate cancer from whom immediate adjuvant radiotherapy would be offered following radical prostatectomy who are instead treated with initial radiotherapy would be also treated with androgen-deprivation therapy for up to 3 years based on the results of EORTC 22863 (Bolla et al, 2002). There is an abundance of data demonstrating the deleritious effects of androgen-deprivation therapy, particularly when taken for longer than 12 months, including osteoporosis, metabolic syndrome, unfavourable body composition, sexual dysfunction, and reduced quality of life (Basaria et al, 2002; Chen and Petrylak 2004; Holzbeierlein et al, 2004; Taylor et al, 2009). Therefore, this analysis likely underestimates the burden of treatment-related complications for men treated with radiotherapy as their primary treatment modality.

In this study, we found that the analysis of patients undergoing radiotherapy using only modern radiotherapy techniques had similar rates of complications as the entire radiotherapy cohort. This result differs from the published literature - Goenka et al (2011) found that the use of intensity-modulated radiation therapy (IMRT) decreased the rates of gastrointestinal and genitourinary toxicities compared with traditional radiotherapy. In addition to a larger sample size, our study included a more extensive definition of treatment-related complications than elsewhere in the literature, which may explain the discrepant findings.

This study is bolstered by the comprehensiveness of the data available in our single-payer health care system (OHIP). Furthermore, we have a large, population-based sample, which reflects real-world practice rather than single, centre-of-excellence care. Although the validity of these administrative data have not been verified with medical chart review, a number of studies have established the validity of using administrative data in Ontario (CIHI, Registered Persons, and physician billings) (Austin et al, 2002; Lee et al, 2005; Tu et al, 2007; Gershon et al, 2009). We were, however, unable to examine the independent effects of adjuvant $v s$ salvage radiotherapy in separate analyses as our population-level databases do not distinguish between them. Furthermore, owing to 
the administrative nature of our data, we lack information on tumour grade, stage, and preoperative PSA in order to provide an assessment of prostate cancer risk. In addition, we do not have access to details such as patient body mass index, prostate volume, radiotherapy field, and case volumes of the treating physicians, which may influence rates of complications. This may present potential confounding that we could not address by the use of propensity-score analysis. We were also unable to assess complications of robotic prostatectomy or IMRT.

Salvage or adjuvant radiation among prostate cancer patients treated with surgery increases the rates of the studied complications; however, complication rates still remain lower than patients treated with radiation alone.

\section{REFERENCES}

Austin PC, Daly PA, Tu JV (2002) A multicenter study of the coding accuracy of hospital discharge administrative data for patients admitted to cardiac care units in Ontario. Am Heart J 144(2): 290-296.

Barry MJ, Albertsen PC, Bagshaw MA, Blute ML, Cox R, Middleton RG, Gleason DF, Zincke H, Bergstralh EJ, Jacobsen SJ (2001) Outcomes for men with clinically nonmetastatic prostate carcinoma managed with radical prostactectomy, external beam radiotherapy, or expectant management: a retrospective analysis. Cancer 91(12): 2302-2314.

Basaria S, Lieb 2nd J, Tang AM, DeWeese T, Carducci M, Eisenberger M, Dobs AS (2002) Long-term effects of androgen deprivation therapy in prostate cancer patients. Clin Endocrinol (Oxf) 56(6): 779-786.

Berrington deGonzalez A, Curtis RE, Kry SF, Gilbert E, Lamart S, Berg CD, Stovall M, Ron E (2011) Proportion of second cancers attributable to radiotherapy treatment in adults: a cohort study in the US SEER cancer registries. Lancet Oncol 12(4): 353-360.

Bianco Jr. FJ, Scardino PT, Eastham JA (2005) Radical prostatectomy: long-term cancer control and recovery of sexual and urinary function ("trifecta"). Urology 66(5 Suppl): 83-94.

Bolla M, Collette L, Blank L, Warde P, Dubois JB, Mirimanoff RO, Storme G, Bernier J, Kuten A, Sternberg C, Mattelaer J, Lopez Torecilla J, Pfeffer JR, Lino Cutajar C, Zurlo A, Pierart M (2002) Long-term results with immediate androgen suppression and external irradiation in patients with locally advanced prostate cancer (an EORTC study): a phase III randomised trial. Lancet 360(9327): 103-106.

Bolla M, van Poppel H, Collette L, van Cangh P, Vekemans K, Da Pozzo L, de Reijke TM, Verbaeys A, Bosset JF, van Velthoven R, Marechal JM, Scalliet P, Haustermans K, Pierart M. R. European Organization for and C. Treatment of (2005) Postoperative radiotherapy after radical prostatectomy: a randomised controlled trial (EORTC trial 22911). Lancet 366(9485): 572-578.

Center H. S. R. D. (2005) The Johns Hopkins ACG Case-Mix System Reference Manual Version 7.0. The Johns Hopkins University Bloomberg School of Public Health: Baltimore, MD, USA.

Chen AC, Petrylak DP (2004) Complications of androgen deprivation therapy in men with prostate cancer. Curr Oncol Rep 6(3): 209-215.

Gershon AS, Wang C, Guan J, Vasilevska-Ristovska J, Cicutto L, To T (2009) Identifying individuals with physcian diagnosed COPD in health administrative databases. COPD 6(5): 388-394.
Goenka A, Magsanoc JM, Pei X, Schechter M, Kollmeier M, Cox B, Scardino PT, Eastham JA, Zelefsky MJ (2011) Improved toxicity profile following high-dose postprostatectomy salvage radiation therapy with intensity-modulated radiation therapy. Eur Urol 60(6): 1142-1148.

Holzbeierlein JM, McLaughlin MD, Thrasher JB (2004) Complications of androgen deprivation therapy for prostate cancer. Curr Opin Urol 14(3): 177-183.

Kibel AS, Ciezki JP, Klein EA, Reddy CA, Lubahn JD, Haslag-Minoff J, Deasy JO, Michalski JM, Kallogjeri D, Piccirillo JF, Rabah DM, Yu C, Kattan MW, Stephenson AJ (2012) Survival among men with clinically localized prostate cancer treated with radical prostatectomy or radiation therapy in the prostate specific antigen era. J Urol 187(4): 1259-1265.

Lee DS, Donovan L, Austin PC, Gong Y, Liu PP, Rouleau JL, Tu JV (2005) Comparison of coding of heart failure and comorbidities in administrative and clinical data for use in outcomes research. Med Care 43(2): $182-188$.

Nam RK, Cheung P, Herschorn S, Saskin R, Su J, Klotz LH, Chang M, Kulkarni GS, Lee Y, Kodama RT, Narod SA (2014) Incidence of complications other than urinary incontinence or erectile dysfunction after radical prostatectomy or radiotherapy for prostate cancer: a population-based cohort study. Lancet Oncol 15(2): 223-231.

Potosky AL, Davis WW, Hoffman RM, Stanford JL, Stephenson RA, Penson DF, Harlan LC (2004) Five-year outcomes after prostatectomy or radiotherapy for prostate cancer: the prostate cancer outcomes study. J Natl Cancer Inst 96(18): 1358-1367.

Sooriakumaran P, Nyberg T, Akre O, Haendler L, Heus I, Olsson M, Carlsson S, Roobol MJ, Steineck G, Wiklund P (2014) Comparative effectiveness of radical prostatectomy and radiotherapy in prostate cancer: observational study of mortality outcomes. BMJ 348: g1502.

Stephenson AJ, Shariat SF, Zelefsky MJ, Kattan MW, Butler EB, Teh BS, Klein EA, Kupelian PA, Roehrborn CG, Pistenmaa DA, Pacholke HD, Liauw SL, Katz MS, Leibel SA, Scardino PT, Slawin KM (2004) Salvage radiotherapy for recurrent prostate cancer after radical prostatectomy. JAMA 291(11): $1325-1332$.

Taylor LG, Canfield SE, Du XL (2009) Review of major adverse effects of androgen-deprivation therapy in men with prostate cancer. Cancer 115(11): 2388-2399.

Thompson Jr. IM, Tangen CM, Paradelo J, Lucia MS, Miller G, Troyer D, Messing E, Forman J, Chin J, Swanson G, Canby-Hagino E, Crawford ED (2006) Adjuvant radiotherapy for pathologically advanced prostate cancer: a randomized clinical trial. J Am Med Assoc 296(19): 2329-2335.

Thompson IM, Tangen CM, Paradelo J, Lucia MS, Miller G, Troyer D, Messing E, Forman J, Chin J, Swanson G, Canby-Hagino E, Crawford ED (2009) Adjuvant radiotherapy for pathological T3N0M0 prostate cancer significantly reduces risk of metastases and improves survival: long-term followup of a randomized clinical trial. J Urol 181(3): 956-962.

Tu K, Campbell NR, Chen ZL, Cauch-Dudek KJ, McAlister FA (2007) Accuracy of administrative databases in identifying patients with hypertension. Open Med 1(1): e18-e26.

This work is published under the standard license to publish agreement. After 12 months the work will become freely available and the license terms will switch to a Creative Commons AttributionNonCommercial-Share Alike 4.0 Unported License. 